\title{
Evaluation of Genetic Diversity Among Kongpo Monkshood (Aconitum kongboense L.) Germplasm Accessions Revealed by Inter Simple Sequence Repeat Markers
}

\author{
Fanjuan Meng, Ruoding Wang, and Mu Peng \\ College of Life Science, Northeast Forestry University, Harbin 150040, China
}

\author{
Chao Wang, Zhongkui Wang, and Fachun Guan \\ Agricultural and Animal Husbandry College of Tibet University, Linzhi \\ 860000, China
}

\section{Yajun $\mathbf{L i}^{1}$}

College of Mathematics, Jilin University, Changchun, 130012, Jilin, PR China

Additional index words. phylogenetic analysis, molecular marker, breeding

\begin{abstract}
Inter simple sequence repeat (ISSR) were used to evaluate the genetic diversity of Kongpo Monkshood (Aconitum kongboense L.) in Motuo, Tibet Plateau. From 70 accessions of three populations, 10 out of 100 informative ISSR primers were chosen for polymorphism analysis. Percentage of polymorphic bands was $50 \%$ to $66.67 \%$ with a mean of $58.42 \%$. The effective number of alleles (Ne) was between 1.545 (population 3 ) and 1.586 (population 2), and the mean value was 1.564; the Nei's gene diversity (h) ranged from 0.315 to 0.327 with the average value of 0.320 ; the value of Shannon's information index (I) ranged from 0.459 to 0.478 , with the mean of 0.469 . Based on molecular data, cluster analysis classified the $\mathbf{7 0}$ cultivars into three groups. Most accessions were related to the geographical origin and their genetic backgrounds. Bayesian structure and PCoA analysis were consistent with the dendrogram result. Based on the analysis, it will provide a reference for Kongpo Monkshood breeding purposes and contribute to identification, rational exploitation, and conservation of germplasms.
\end{abstract}

Kongpo Monkshood (Aconitum kongboense L.), native to China, are mostly used as folk medicine to treat arthritis pain (Meng et al., 2014; Xiao et al., 2006). It has a large genus with $\approx 300$ species that widespread distribute in the temperate regions of the Northern Hemisphere. China, particularly in Hengduan Mountains region, is the most important center of diversity and speciation of this genus, such as Yunan, Sichuan, and Xizang. The root tuber of this perennial plant possesses many kinds of diterpenoid alkaloids including vilmorrianine A, kongboenine, chasmaconitine, talatisamine (Wang, 2001). Now, mostly studies in Kongpo Monkshood were focus on its taxonomic (Wang et al., 2009), pharmacophylogenetic study (Xiao et al., 2006), and aconitine extraction (Beike et al., 2004).

ISSR marker is considered as a simple and quick technique that combines most of the

Received for publication 19 Mar. 2015. Accepted for publication 7 Apr. 2015

This study was supported by the Fundamental Research Funds for the Central Universities (No. 2572015DA03; DL13EA08-02), the National Natural Science Foundation of China (31360073 and 31201594), and Technology Services Network Program of the Chinese Academy of Sciences (KFJ-EW-STS-073).

${ }^{1}$ To whom reprint requests should be addressed; e-mail L19813211@163.com. samples used in the present studies was shown in Table 1.

DNA extraction. For the all samples, fresh leaf tissues were randomly harvested from healthy and mature plant, and stored in sealed plastic bags. Then the sampled tissues were frozen in $-80{ }^{\circ} \mathrm{C}$. Genomic DNA was isolated from $0.1 \mathrm{~g}$ leaf tissue using CTAB method of Doyle (1990). DNA was checked by electrophoresis on $1.0 \%$ agarose gels, and detected quantificationally by a spectrophotometer (ultraviolet-1800, Japan). Finally, DNA samples were diluted to $50 \mathrm{ng} / \mu \mathrm{L}$ and then stored at $-20{ }^{\circ} \mathrm{C}$ for polymerized chain reaction (PCR) amplification.

ISSR markers and PCR amplification. ISSR reaction was performed as previously described by Wang et al. (2013) with minor modifications. The ISSR-PCR optimized reaction conditions included a total volume of $25 \mu \mathrm{L}$ containing $50 \mathrm{ng}$ template DNA, $10 \mathrm{pmol}$ each primer, 1x PCR Buffer, $0.25 \mathrm{~mm}$ of each dNTP, $2.5 \mathrm{~mm} \mathrm{Mg}^{2+}$, and 0.2 U Taq DNA polymerase (TakaRa, Japan). All amplification reactions were conducted with a PCR Thermal Cycler Dice (TakaRa, Japan). The cycling conditions were as follows: $5 \mathrm{~min}$ at $94{ }^{\circ} \mathrm{C}$ for an initiation step, 40 cycles of $1 \mathrm{~min}$ at $94{ }^{\circ} \mathrm{C}$, $1 \mathrm{~min}$ at a primer-appropriate temperature, $1 \mathrm{~min}$ at $72{ }^{\circ} \mathrm{C}$, and a final cycle of $10 \mathrm{~min}$ at $72{ }^{\circ} \mathrm{C}$. PCR products were detected by $2.0 \%$ agarose gel with $0.5 \mu \mathrm{L} / \mathrm{mL}$ GelRed and photographed by Bio-image Systems (GG/D2-GeneGnius2).

Analysis of amplification profiles. Each bands that were amplified with ISSR primers, were scored manually as present (1) or absent (0) in each primer to produce a set of binary code for ISSR analysis. Only those fragments that were reproducible and clear were considered for scoring. To estimate the genetic diversity of Kongpo Monkshood, genetic parameters including observed number of alleles $(\mathrm{Na})$, effective number of alleles $(\mathrm{Ne})$, Nei's gene diversity (h), Shannon's information index $(I)$, the number of polymorphic loci (NPL), and the percentage of polymorphic loci (PPL) of populations, Nei's genetic differentiation index (Gst), and gene flow $(\mathrm{Nm})$ were calculated using PopGene32 software (version 1.32). The molecular marker data were analyzed at both individual and population levels. Genetic variances among and within populations were analyzed to assign components of genetic variation to hierarchical sets of populations using analysis of molecular variance (AMOVA) 1.55 software (Yeh et al., 1999). To assess the genetic relationships among individuals, unweighted pair group method with arithmetic mean (UPGMA) and principle coordinate analysis (PCoA) were performed based on Nei's genetic distance (Nei, 1973) using the NTSYS-pc version 2.10s software (Rohlf, 2000) to generate three-dimensional (3D) scatter plots. Correlation analysis was carried out with the SPSS statistics software 17.0 (Nie et al., 1975).

\section{Results}

\section{Materials and Methods}

Plant materials. A panel of 70 Kongpo Monkshood accessions from three different sites was collected in the Tibet Autonomous Region, China. The detailed description of
ISSR amplification. In this work, 10 out of 100 ISSR primers were used here, which could product clear, identifiable, reproducible, and relatively high polymorphism. One hundred and one clearly identifiable bands in a size 
Breeding, Cultivars, Rootstocks, and Germplasm Resources

Table 1. Locations and sample size of 70 accessions in the study.

\begin{tabular}{lcccccc}
\hline Population no. & Code & Sample size & Location & Longitude $(\mathrm{E})$ & Latitude $(\mathrm{N})$ & Altitude $(\mathrm{m})$ \\
\hline 1 & $\mathrm{~s}$ & 15 & Jiazha village, Cuijiu country, Tibet, China & 29.29 & 92.72 \\
2 & $\mathrm{k}$ & 26 & Langkazi village, Kare country, Tibet, China & 29.26 & 3,260 \\
3 & $\mathrm{~m}$ & 29 & Zhaxue village, Mozu country, Tibet, China & 30.08 & 90.42 & 4,500 \\
\hline
\end{tabular}

Table 2. Information on inter simple sequence repeat primers among three populations used in this study.

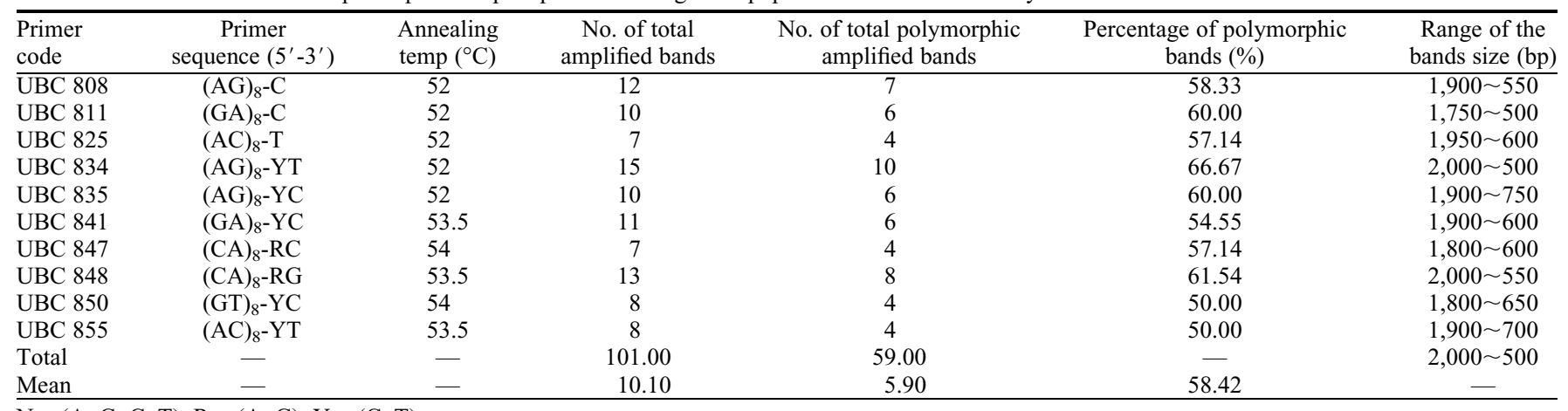

$\mathrm{N}=(\mathrm{A}, \mathrm{G}, \mathrm{C}, \mathrm{T}), \mathrm{R}=(\mathrm{A}, \mathrm{G}), \mathrm{Y}=(\mathrm{C}, \mathrm{T})$.

range from 500 to 2000 base pair (bp) were obtained using the 10 primers (Table 2). Among the amplified fragments, 59 bands were polymorphic ranged from 4 to 10 with an average of 5.9 per primers, and the percentage of polymorphism were $50 \%$ to $66.67 \%$ with a mean of $58.42 \%$. From the 10 ISSR primers, no population-specific fragments were observed.

The genetic diversity analysis was tested according to geographic area, and its results were shown in Table 3 . All parameters showed that there were no significant differences among three areas. The observed number of alleles $(\mathrm{Na})$ of the three geographical groups was ranked as follows: population $3>$ population $2>$ population 1 . The effective number of alleles $(\mathrm{Ne}$ ) was between 1.545 (population 3) and 1.586 (population 2); the Nei's gene diversity (h) ranged from 0.315 to 0.327 with the average value of 0.320 ; the value of Shannon's information index $(I)$ ranged from 0.459 to 0.478 ; the percentage of polymorphic loci of 70 accessions had a higher value, ranging from $77.59 \%$ to $87.93 \%$, with an average of $82.76 \%$. In addition, Nei's genetic differentiation index (Gst) was 0.1942, and the estimate of gene flow was more than $1(\mathrm{Nm}, 2.0750)$.

Correlation analysis showed that the differences in Nei's genetic diversity among the three populations were highly significant negatively related to their geographical distances $(r=$ $-1.00, P<0.01$ ) (Fig. 1A), whereas it was significantly correlated with the location altitude $(r=0.95, P<0.05)$ (Fig. 1B).

Genetic variation and genetic relatedness assay of Aconitum kongboense. To illusion the genetic variation among and within populations, AMOVA was carried out, and the results were presented in Table 4 . Of the total genetic diversity, $22.25 \%$ of genetic variation resided among populations, whereas $77.75 \%$ existed within populations. Consequently, genetic variation of $A$. kongboense mainly existed in within populations.

Genetic relationship assays of the $70 \mathrm{~A}$. kongboense accessions were conducted using UPGMA dendrogram based on Jaccard's similarity coefficients (Fig. 2). The similarity
Table 3. the genetic parameters of tested populations from different geographic areas in the study.

\begin{tabular}{lcccccc}
\hline Population name & $N a$ & $N e$ & $h$ & $I$ & NPL & PPL (\%) \\
\hline Population 1 & $1.776 \pm 0.421$ & $1.560 \pm 0.368$ & $0.315 \pm 0.191$ & $0.459 \pm 0.268$ & 45 & 77.59 \\
Population 2 & $1.828 \pm 0.381$ & $1.586 \pm 0.373$ & $0.327 \pm 0.185$ & $0.478 \pm 0.253$ & 48 & 82.76 \\
Population 3 & $1.879 \pm 0.329$ & $1.545 \pm 0.356$ & $0.319 \pm 0.170$ & $0.470 \pm 0.227$ & 51 & 87.93 \\
Mean & 1.828 & 1.564 & 0.320 & 0.469 & 48 & 82.76 \\
\hline
\end{tabular}

$\mathrm{Na}$ : observed number of alleles, $\mathrm{Ne}$ : effective number of alleles, $h$ : Nei's gene diversity, $I$ : Shannon's information index, NPL: the number of polymorphic loci, PPL: the percentage of polymorphic loci.
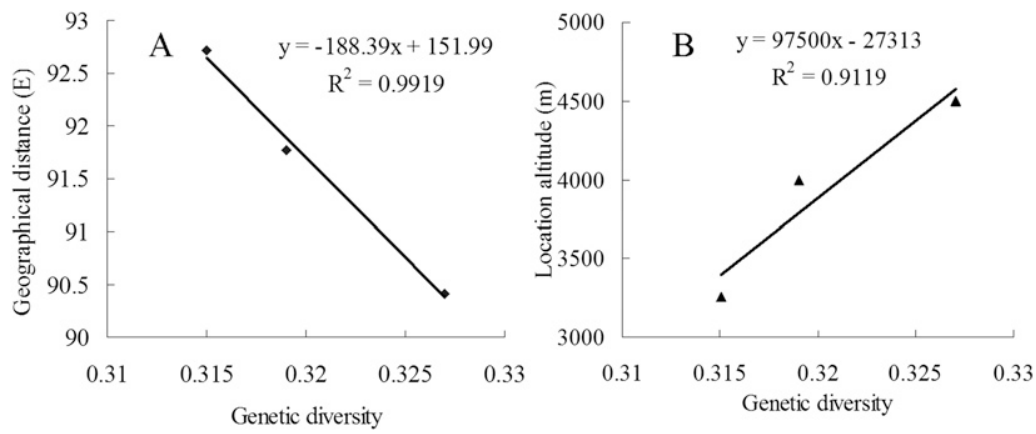

Fig. 1. Correlation analysis between Nei's genetic diversity with samples collected at geographical distance (A) and site's altitude (B).

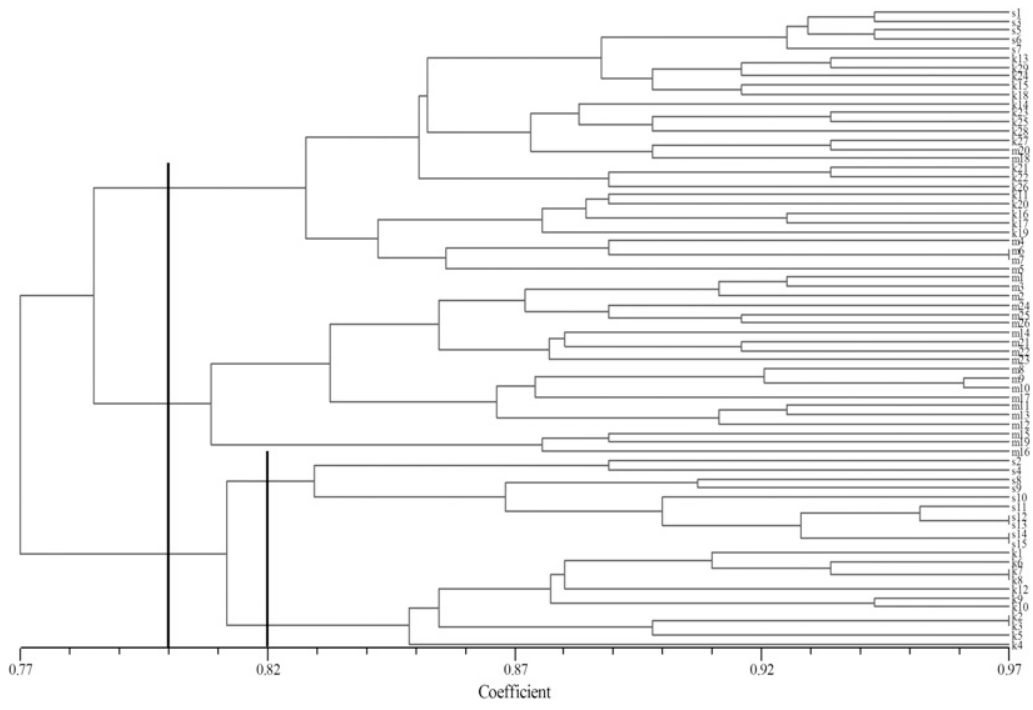

Fig. 2. Dengrogram based on Jaccard's coefficient. s1-s15: samples from Jiazha village, k1-k29: samples from Langkazi village, m1-m26: samples from Zhaxue village. 
coefficients among all populations ranged from 0.77 to 0.97 , with an average value of 0.87. According to UPGMA dendrogram analysis, 70 samples were clustered into three groups in a common node at similarity coefficient of 0.80 . Group I included 29 accessions, with 5 from Jiazha village, 6 from Langkazi village, and 18 from Zhaxue village. Twenty cultivars from Langkazi village belonged to Group II. Group III consisted of 21 samples, 10 from Jiazha village and 11 from Langkazi village. Furthermore, Group III was further subdivided into two subgroups. Ten $A$. kongboense cultivars were in the subgroup A together. Subgroup B included 11 populations from Langkazi village. There appeared to be significant sampling localities clustering overall.

To analyze hierarchical population structure of all samples, a Bayesian structure was performed by structure 2.1 based on a mathematic model (Fig. 3). The results demonstrated that model with $K=3$ explained the data satisfactorily, suggesting that the most likely number of accessions was three, which calculated by the log probability of data for the value of $K$. Red, blue, and green color vertical bars represented the genotypes. Additionally, in the PCoA analysis, 70 individuals were clearly separated into three distinct groups, which in was accordant with the UPGMA cluster analysis (Fig. 4).

\section{Discussions}

ISSR is known as its effectiveness and practicability for identifying genetic diversity and assessing genetic variations in many plant species (Wang et al., 2013; Zhao et al., 2014). Therefore, in the present study, ISSR markers were the firstly used to analyze the genetic diversity of Kongpo Monkshood cultivars, and our results showed that high polymorphism existed in these germplasm.

Genetic diversity plays an important role in plant evolution; both adaptation and speciation depend upon genetic diversity (Amos and Harwood, 1998; Jiang et al., 2012). In this study, based on ISSR data, a higher percentage of polymorphism (58.42\%) was found in the 70 individuals, suggesting that accessions possessed a relatively high degree of genetic diversity (Table 2). However, the degree of diversity was lower than the values previously reported in other species with the same family, such as A. carmichaeli Debx (83.5\%) (Tian, 2007), A. leucostomum (88.1\%) (Gao et al., 2014). The possible reason was due to long-term hostile environmental conditions and disturbance by human activities (immoderate collection). As we know, Qinghai-Tibet plateau, averaging over $4000 \mathrm{~m}$ above sea level and covering an area of $200,000 \mathrm{~km}^{2}$, has the complex geological features with vagaries of climate. Although grown in this area, the same species, however, possessed significant difference in genetic diversity (Wang and Ding, 2007).

At the population level (Table 3), in population 1 , the lowest indices, including $N a$ (1.776), $h$ (0.315), I (0.459), NPL (45),
Table 4. Analysis of molecular variance for 70 individuals used in this study.

\begin{tabular}{lrccccc}
\hline $\begin{array}{l}\text { Source of } \\
\text { variance }\end{array}$ & df & $\begin{array}{c}\text { Sum of squared } \\
\text { deviations }\end{array}$ & $\begin{array}{c}\text { Mean } \\
\text { squares }\end{array}$ & $\begin{array}{c}\text { Variance } \\
\text { component }\end{array}$ & $\begin{array}{c}\text { Percentage } \\
\text { total (\%) }\end{array}$ & $P$ value* \\
\hline Among populations & 2 & 794.77 & 397.39 & 2.77 & 22.25 & $<0.001$ \\
Within populations & 69 & 650.12 & 9.42 & 9.70 & 77.75 & $<0.001$ \\
\hline
\end{tabular}

$\mathrm{df}=$ degrees of freedom.

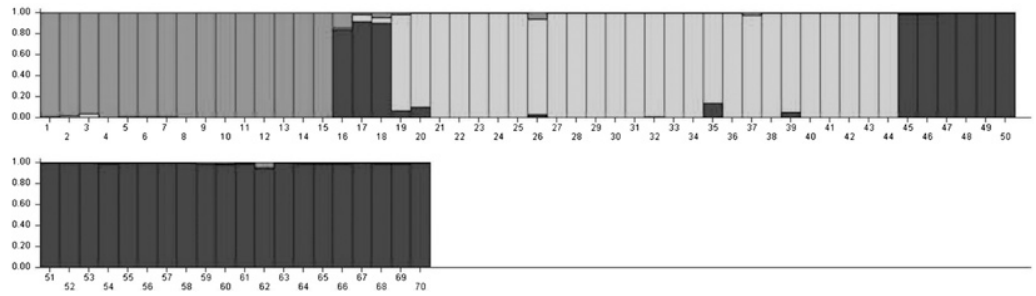

Fig. 3. Bayesian analysis of population structure for $K=3$ based on ISSR data. Each vertical bar represents a genotype. 1-15: samples from Jiazha village, 16-41: samples from Langkazi village, 42-70: samples from Zhaxue village.

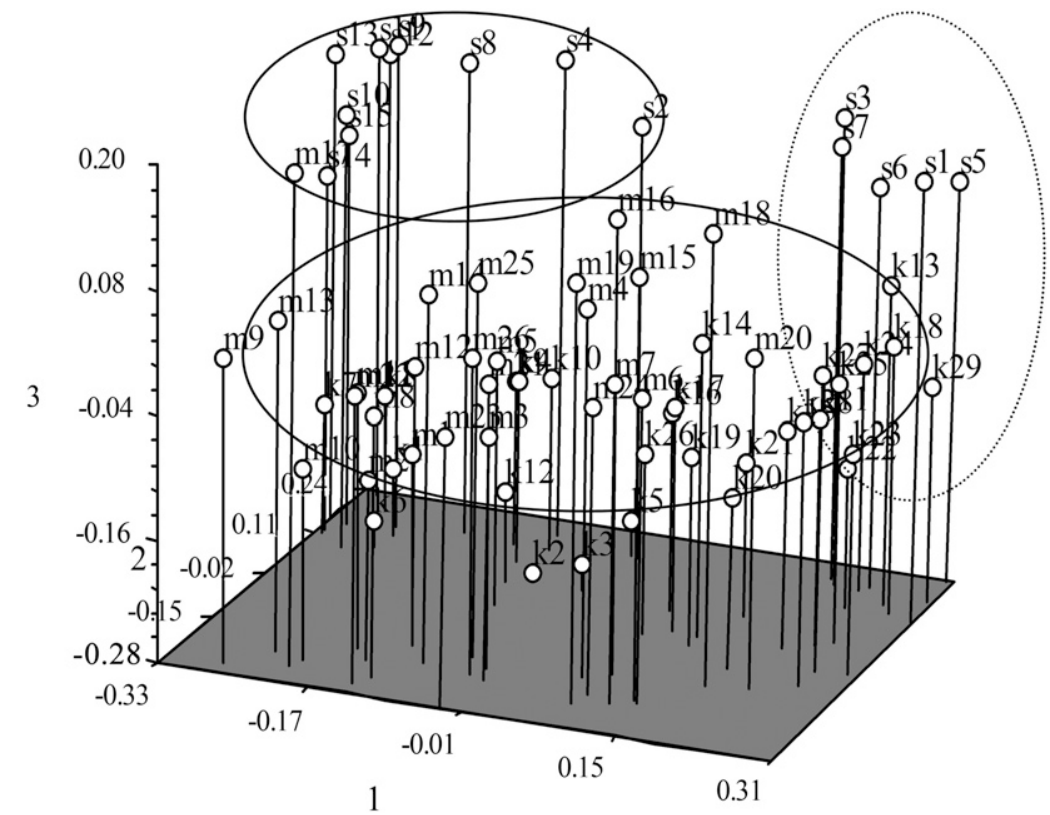

Fig. 4. Principal coordinates analysis for the inter simple sequence repeat evolution of Kongpo Monkshood accessions.

PPL (77.59), were detected in this group while some parameters were the highest in population 3 with $\mathrm{Na}$ (1.879), NPL (0.319), PPL (87.93\%). Actually, population 2 also had some high values, such as $N e, h, I$. Compared with the lower polymorphisms at RAPD loci reported in A. carmichaeli Debx accessions, Zhang et al. (2009) found polymorphic proportion with $24.95 \%, 50.63 \%$, and $50.46 \%$ in different populations. Hu et al. (2014) estimated that this species possessed percentage of polymorphism with a value of $78.2 \%$. Therefore, our study results had a higher value of polymorphism, implying that the diversity of each population was possibly affected by its location. Furthermore, the higher value could be attributed to a wide range of geographical distribution, which has been shown to effectively change in a large population (Hamrick and Godt, 1996).
Correlation analysis showed significantly related to Nei's genetic diversity of all populations and their corresponding location altitudes $(r=0.95, P<0.05)$ (Fig. 1), which further confirmed the higher value caused by geographical distribution. Guan et al. (2014) concluded that sites with higher altitudes $(4000-5000 \mathrm{~m})$ were much more evolution and genetic variability than those from lower altitudes. In this study, both population 2 and population 3 collected from higher altitudes that tolerate by strongly intensity of ultraviolet radiation and could be induced to produce a variety of genetic variations. Therefore, these two populations possessed higher genetic diversities. On the contrary, population 3 is distributed in a lower altitude, which could be largely affected by human activities. Because geographical distances is a vital factor for driving genetic diversity of populations, the correlation analysis was also detected in our 
work $(r=-1.00, P<0.01)$. A highly significant negative correlation was obtained in the populations (Fig. 1A). The same point could be found in Wang et al. (2013) and Guan et al. (2014). The significant result suggested that samples collected in different places have a large influence on the population structure of Kongpo Monkshood.

A high level of genetic variability is seen as health indicator and confers the ability to respond to environmental changes (Amos and Harwood, 1998; Fielder et al., 2015). Estimates within population variation based on the ISSR markers were higher than the values with dominant markers (AFLP) (Meng et al., 2014), which was $52.77 \%$ of genetic variation resided among populations and $47.23 \%$ existed within populations in AFLP, whereas $22.25 \%$ and $77.75 \%$ in corresponding parts with ISSR markers, respectively (Table 4), and our results were consistent with a lower $G s t$ values (0.1942). Additionally, $\mathrm{Nm}$ was higher than 1 and suggested strong gene flow among widely distributed populations. As the high variability of mostly molecular markers (RAPD, ISSR, AFLP, or SSR), the values of within population variation were often much higher than those in among population variation (Fang et al., 2012; Nybom, 2004).

Aconitum L. is difficult to classify even though at level of genus, because of different classification standard, species traits' variation, and lacking of correlation among them. Therefore, researches have conducted many works in taxonomical study of Aconitum L., including classic taxonomy, morphology, cytology, molecular systematic, and biochemistry in traditionally (Luo et al., 2005; Song et al., 2012; Xiao et al., 2006). However, this species classification has not reached a consensus so far. Now, cluster analysis was considered as an effective tool for cultivar classification (Fang et al., 2012). Some results were obtained the cultivar classification based on molecular markers (Tian et al., 2007). Based on ISSR data, three clustering methods used in this study were generated for revealing clear relationship among populations. The analysis results suggested groups significantly related to their geographical area, which reflected the geographic distribution patterns in Kongpo Monkshood (Fig. 2). Group I, II, III populations, in the UPGMA dendrogram, cultivated on the high altitudes area $\approx 4000 \mathrm{~m}, 4500 \mathrm{~m}$, $3260 \mathrm{~m}$, respectively. For Bayesian clustering (Fig. 3) and PCoA analysis (Fig. 4), the results of relationship were consistent with the dendrogram. Interestingly, the phylogenic analysis of ISSR was agreement with known pedigrees and previous marker evolution (Luo et al., 2005; Tian et al., 2007). The genetic relationship revealed by ISSR markers should thus be beneficial to Kongpo Monkshood breeding programs in the future.
This study, the first report on Kongpo Monkshood from Tibet Plateau, can contribute to our knowledge of genetic diversity and relationship among this species. Using ISSR markers, we efficiently and successfully detected genetic variation among Kongpo Monkshood individuals. Finally, our findings will help for breeding and conservation of Kongpo Monkshood.

\section{Literature Cited}

Amos, W. and J. Harwood. 1998. Factors affecting levels of genetic diversity in natural populations. Philos. Trans. R. Soc. Lond. B Biol. Sci. 353:177-186.

Beike, J., L. Frommherz, M. Wood, B. Brinkmann, and H. Köhler. 2004. Determination of aconitine in body fluids by LC-MS-MS. Intl. J. Legal Med. 118:289-293.

Doyle, J.J. 1990. Isolation of plant DNA from fresh tissue. Focus 12:13-15.

Fang, W., H. Cheng, Y. Duan, X. Jiang, and X. Li. 2012. Genetic diversity and relationship of clonal tea (Camellia sinensis) cultivars in China as revealed by SSR markers. Plant Syst. Evol. 298:469-483.

Fielder, A.L., J. Coller, M. Hutchinson, R.R. Haslam, N. Lu, S. Adeniyi-Jones, M. Ehrlich, and W.K. Kraft. 2015. Neonatal abstinence syndrome in methadone exposed infants: Role of genetic variability. Drug Alcohol Depend. 146:e277.

Gao, F., Y. Sun, J. Zhang, and F. Zhang. 2014. ISSR analysis for genetic polumorphism of Aconitum leucostomum from different habitats. Journal of Chinese Medicinal Materials $37: 26-29$.

Guan, F.C., S.P. Wang, R.Q. Li, M. Peng, and F.J. Meng. 2014. Genetic diversity of wild peach (Prunus mira koehne kov et. kpst) from different altitudes in the Tibetan Plateau by pollen morphous and RAPD markers. HortScience 49:1-6.

Hamrick, J.L. and M.J. Godt. 1996. Effects of life history traits on genetic diversity in plant species. Philos. Trans. R. Soc. Lond. B Biol. Sci. 351:1291-1298.

Hu, P., Y.L. Xia, Y.X. Yang, X.J. Zhou, and G.M. Shu. 2014. Genetic diversity among Aconitum carmichaeli Debx. germplasm based on RAMP markers. Xi Nan Nong Ye Xue Bao 27:984990.

Jiang, Z., Y. Chen, and Y. Bao. 2012. Population genetic structure of Tamarix chinensis in the Yellow River Delta, China. Plant Syst. Evol. 298:147-153.

Linos, A., N. Nikoloudakis, A. Katsiotis, and M. Hagidimitriou. 2014. Genetic structure of the Greek olive germplasm revealed by RAPD, ISSR and SSR markers. Sci. Hort. 175:33-43.

Luo, Y., F.M. Zhang, and Q.E. Yang. 2005. Phylogeny of Aconitum subgenus Aconitum (Ranunculaceae) inferred from ITS sequences. Plant Syst. Evol. 252:11-25.

Mao, L.H. and Y.M. Fang. 2014. ISSR primer screening and preliminary evaluation of genetic diversity in Haplocladium microphyllum. Biochem. Syst. Ecol. 55:107-111.

Meng, F., M. Peng, R. Wang, C. Wang, and F. Guan. 2014. Analysis of genetic diversity in
Aconitum kongboense L. revealed by AFLP markers. Biochem. Syst. Ecol. 57:388-394.

Nei, M. 1973. Analysis of gene diversity in subdivided populations. Proc. Natl. Acad. Sci. USA 70:3321-3323.

Nie, N.H., D.H. Bent, and C.H. Hull. 1975. SPSS: Statistical package for the social sciences. McGraw-Hill, New York, NY.

Nybom, H. 2004. Comparison of different nuclear DNA markers for estimating intraspecific genetic diversity in plants. Mol. Ecol. 13:1143-1155.

Reddy, M.P., N. Sarla, and E.A. Siddiq. 2002. Inter simple sequence repeat (ISSR) polymorphism and its application in plant breeding. Euphytica 128:9-17.

Rohlf, F. 2000. NTSYS-PC, numerical taxonomy and multivariate analysis system for the PC ExeterSoftware, Version 2.1. Applied Biostatistics, Inc., Setauket, NY.

Song, Y., Y.G. Qiao, and Y.X. Wu. 2012. Clustering analysis of karyotype resemblance-near coefficient of 16 Aconitum L. species. Acta Agrestia Sinica 20:352-357.

Tian, M.L., Y.Q. Tian, F. Liu, and Y.B. Huang. 2007. The genetic diversity of germplasms of Aconitum carmichaeli Debx. revealed by RAPD markers. J. Sichuan Agr. Univ. 25:6367.

Tian, Y. 2007. Study on rapid propagation seedings of Aconitum carmichaeli Debx. and analysis of the germplasm by RAPD and AFLP markers. Sichuan Agricultural University, Sichuan, Master Diss.

Wang, A.H. and Y. Ding. 2007. Genetic diversity of wild close relatives of barley (Hordeum vulgare L.) in Tibet of China by using RAPD and ISSR markers. J. Wuhan Univ. 53:723730.

Wang, C., G.R. Li, Z.Y. Zhang, M. Peng, Y.S. Shang, R. Luo, and Y.S. Chen. 2013. Genetic diversity of castor bean (Ricinus communis L.) in Northeast China revealed by ISSR markers. Biochem. Syst. Ecol. 51:301-307.

Wang, F. 2001. Chemical study on the norditerpenoid alkaloids of Aconitum kongboense. Natural Product Research and Development 14: 37-39.

Wang, L., R.J. Abbott, W. Zheng, P. Chen, Y. Wang, and J. Liu. 2009. History and evolution of alpine plants endemic to the QinghaiTibetan Plateau: Aconitum gymnandrum (Ranunculaceae). Mol. Ecol. 18:709-721.

Xiao, P.G., Q. Wang, F. Gao, L.P. Yan, D.L. Chen, and Y. Liu. 2006. A pharmacophlogenetic study of Aconitum L. (Ranunculaceae) from China. Acta Phytotaxonomica Sinica 44:1-46.

Yeh, F.C., R.C. Yang, T. Boyle, Z.H. Ye, and J.X Mao. 1999. POPGENE, version 1.32: The user friendly software for population genetic analysis. Molecular Biology and Biotechnology Centre, Univ. Alberta, Edmonton, AB, Canada.

Zhang, D., F. Shen, J. Liu, and J. Falandysz. 2014 Studies on germplasm resources of Auricularia polytricha by Inter-Simple Sequence Repeat (ISSR). Med. Eng. Bioinform. 19:1.

Zhang, T., X.S. Li, and H.C. Lu. 2009. Analysis of genetic diversity of A. carmichaeli Debx in Qingba area. Jiangsu J. Agr. Sci. 2:46-48.

Zhao, L., H. Liu, G. Cai, and M. Xia. 2014. Assessment of the genetic diversity and genetic relationships of Lilium in China using ISSR markers. Biochem. Syst. Ecol. 55:184-189. 